\title{
Carbonato de dimetilo como aditivo a combustible diésel para reducir las emisiones de hollín
}

\author{
Katiuska Alexandrino, Ángela Millera, Rafael Bilbao, María U. Alzueta \\ Grupo de Procesos Termoquímicos (GPT). \\ Instituto de Investigación en Ingeniería de Aragón (I3A). \\ Universidad de Zaragoza, Mariano Esquillor s/n, 50018, Zaragoza, España. \\ Tel. +34-976762707, e-mail: katyalex@unizar.es.
}

\section{Resumen}

En el presente trabajo se estudia la tendencia a formar hollín del carbonato de dimetilo (DMC) mediante experimentos de pirólisis, en un reactor de flujo, a diferentes temperaturas. Los resultados indican la baja tendencia a formar hollín que tiene el DMC, mostrándolo como un buen candidato para reducir las emisiones de hollín de los motores diésel.

\section{Introducción}

Las emisiones de los motores diésel son consideradas una de las principales fuentes de contaminación atmosférica, por lo que las investigaciones sobre la reducción de estas emisiones, en especial de la materia particulada (MP u hollín) y de los óxidos de nitrógeno $\left(\mathrm{NO}_{\mathrm{x}}\right)$, son fundamentales para el bienestar de las personas y su salud, así como también para el medio ambiente.

Debido a la dificultdad en reducir conjuntamente las emisiones de MP y $\mathrm{NO}_{\mathrm{x}}$, los vehículos diésel suelen combinar el uso de dos técnicas para reducir las emisiones de ambos contaminantes al mismo tiempo. Principalmente se utilizan dos combinaciones: (1) recirculación de gases de escape para reducir los $\mathrm{NO}_{\mathrm{x}}$ y filtros de partículas diésel para reducir la MP, e (2) inyección a alta presión del combustible para controlar la MP y reducción catalítica selectiva para reducir los $\mathrm{NO}_{\mathrm{x}}$. A pesar de que estas técnicas reducen las emisiones de contaminantes, sus altos costes económicos, así como también la reducción de la efectividad del motor, hacen con que se busquen nuevas alternativas.

Los aditivos oxígenados han demostrado disminuir las emisiones de MP emitidas por los motores diésel. Incluso algunos estudios han demostrado que el uso de compuestos oxigenados reduce las emisiones de MP sin perjudicar las emisiones de $\mathrm{NO}_{\mathrm{x}}$ (e.g. [1]).
Debido a su alto contenido en oxígeno (aproximadamente $53 \%$ en masa), el DMC ha ganado interés como combustible o como aditivo a combustibles convencionales en los últimos años. Numerosos estudios en motores diésel han demostrado que el DMC puede reducir las emisiones de MP (e.g. [2]). Sin embargo, algunos estudios se contradicen en relación a las emisiones de $\mathrm{NO}_{\mathrm{x}}[2-4]$.

El conocimiento de la tendencia a formar hollín de los compuestos oxígenados propuestos como combustible o como aditivo a combustibles convencionales es de fundamental interés. En este contexto, este trabajo se centra en el estudio de la formación de hollín en la pirólisis de DMC.

\section{Experimental}

Los experimentos de pirólisis se han realizado con $3.3 \%$ (vol.) de DMC diluido en $\mathrm{N}_{2}$, con un caudal total de $1000 \mathrm{mLN} / \mathrm{min}$, y en un intervalo de temperatura de 1075-1475 K. La instalación experimental utilizada consta de: (a) un sistema de alimentación de gases que está constituido por controladores de flujo másico y una bomba HPLC unida a una línea calorifugada; (b) un sistema de reacción que cuenta con un horno de alta temperatura y un reactor de cuarzo; (c) un sistema de recolección de hollín que consiste en un filtro localizado a la salida del reactor y (d) un sistema de cuantificación de gases conformado por un cromatógrafo de gases. Una explicación más detallada del sistema experimental se muestra en trabajos anteriores (e.g.[5]).

\section{Resultados y discusión}

La Figura 1 muestra el rendimiento porcentual a hollín y a gases en la pirólisis de 3.3 \% (vol.) de DMC. Se observa que a medida que aumenta la temperatura, el rendimiento a hollín aumenta y el rendimiento a gas disminuye, debido a que el 
carbono presente en el DMC está siendo convertido a hollín y hay menos carbono disponible para formar gases.

El DMC muestra muy baja tendencia a formar hollín, ya que a la máxima temperatura estudiada $(1475 \mathrm{~K})$ el rendimiento a hollín es de apenas $9 \%$, aproximadamente, a hollín. Esta baja tendencia a formar hollín puede comprobarse en la Figura 2, donde se compara el rendimiento a hollín en la pirólisis de $3.3 \%$ (vol.) de DMC y de $5 \%$ (vol.) de etanol (estas concentraciones corresponden a 100000 ppm de carbono) en el intervalo de temperatura 1275-1475 K. Es importante mencionar que el tiempo de residencia en la pirólisis de etanol (1.06-1.23 s) fue mucho menor que en el de la pirólisis de DMC (2.82-3.27 s). Teniendo en cuenta que en estudios anteriores se ha encontrado que un menor tiempo de residencia produce menos hollín [5], se puede concluir que el DMC tiene muy baja tendencia a formar hollín, ya que el etanol, a pesar de que su pirólisis se realizó con menor tiempo de residencia, alcanza un rendimiento a hollín de aproximadamente $30 \%$ a $1475 \mathrm{~K}$.

Esta baja tendencia a formar hollín por parte del DMC puede deberse a su estructura molecular. Este compuesto no contiene enlaces C-C, lo cual favorece la formación de precursores de hollín. Además, su estructura favorece la formación de CO y $\mathrm{CO}_{2}$, quedando menos carbono disponible para formar hollín.

Adicionalmente, se han analizado los principales gases obtenidos en el proceso $\left(\mathrm{C}_{2} \mathrm{H}_{4}, \mathrm{C}_{2} \mathrm{H}_{2}, \mathrm{C}_{6} \mathrm{H}_{6}\right.$, $\mathrm{CH}_{4}, \mathrm{H}_{2}, \mathrm{CO}$ y $\mathrm{CO}_{2}$ ). Se ha observado un máximo en los perfiles de concentración en función de la temperatura para $\mathrm{C}_{2} \mathrm{H}_{4}, \quad \mathrm{C}_{2} \mathrm{H}_{2} \quad$ y $\quad \mathrm{C}_{6} \mathrm{H}_{6} . \quad \mathrm{La}$ disminución de la concentración de estas especies se debe a su participación en el proceso de formación de precursores de hollín.

\section{Conclusiones}

Los resultados de la pirólisis de DMC soportan lo señalado en investigaciones anteriores de que la formación de hollín aumenta con el aumento de la temperatura, mientras el rendimiendo a gas disminuye. Se comprueba la baja tendencia a formar hollín del DMC, que es incluso menor que la del etanol, el combustible/aditivo oxigenado más utilizado en la actualidad.

\section{Agradecimientos}

Los autores expresan su gratitud al Gobierno de Aragón y al Fondo Social Europeo (grupo GPT), a MINECO y a FEDER (CTQ2015-65226) por la financiación concedida. K. Alexandrino agradece a MINECO por su beca pre-doctoral (BES-2013063049).

\section{REFERENCIAS}

[1]. GILL, S.S, TSOLAKIS A, HERREROS J.M, YORK, A.P.E. Diesel emissions inprovements through the use of biodiesel or oxygenated blending components. Fuel. 2012, 95, 578-586.

[2]. ROUNCE, P, TSOLAKIS, A, LEUNG, P, YORK, A.P.E. A comparison of diesel and biodiesel emissions using dimethyl carbonate as an oxygenated additive. Energy Fuels. 2010, 24, 4812-4819.

[3]. LU, X, YANG, J-G, ZHANG, W-G, HUANG, Z. Improving the combustion and emissions of direct injection compression ignition engines using oxygenated fuel additives combined with a cetane number improver. Energy Fuels. 2005, 19, 1879-1888.

[4]. XIAOLU, L., HONGYAN, C., ZHIYONG, Z., ZHEN, H. Study of combustion and emissions characteristics of a diesel operated with dimethyl carbonate. Energ. Convers. Manage. 2006, 47, 1438-1448.

[5]. RUIZ, M.P, VILLORIA, R.G, MILlERA, Á, ALZUETA, M.U, BILBAO R. Influence of different conditions on soot formation from $\mathrm{C}_{2} \mathrm{H}_{2}$ pyrolysis. Ind Eng Chem Res. 2007, 46, 7550-7560.

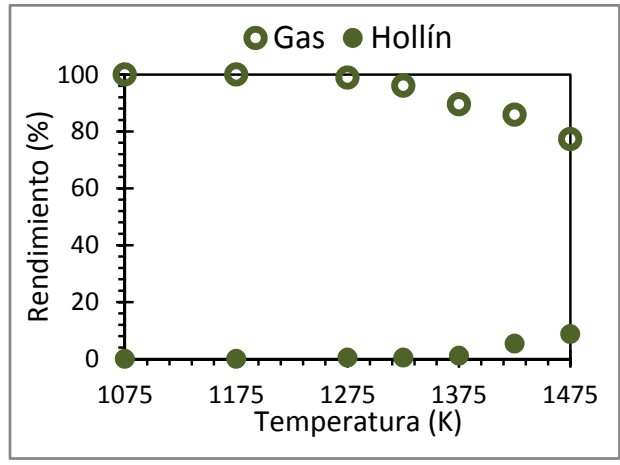

Figura 1. Rendimiento a hollín y a gas en la pirólisis de $3.3 \%$ (vol.) de DMC.

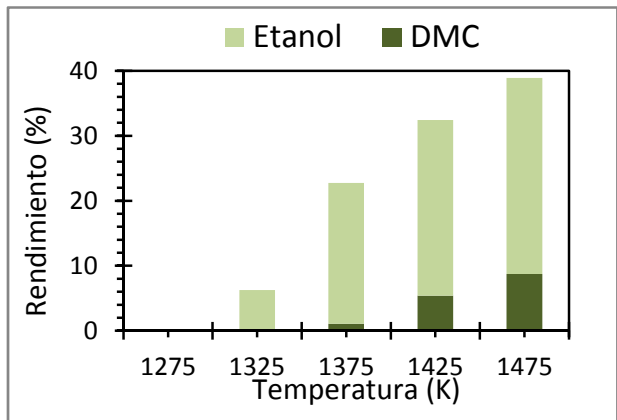

Figura 2. Comparación del rendimiento a hollín en la pirólisis de DMC y etanol. 